\title{
Morphology of Postpollination Fruit Abortion in Pecan
}

\author{
I.E. Yates \\ Russell Research Center, Agricultural Research Service, U.S. Department of Agriculture, Athens, GA 30613 \\ Darrell Sparks \\ Department of Horticulture, University of Georgia, Athens, GA 30602
}

Additional index words. Carya illinoensis, microscopy, zygote, endosperm, fertilization, embryo, cotyledon

\begin{abstract}
Anatomy of normal and abortive fruit was compared at each of the three postpollination fruit drops characteristic of pecan [Carya illinoensis (Wangenh.) C. Koch]. Size differences between normal and abortive fruit decreased during the growing season, but differences in ovule size between normal and abortive fruit increased. During Drop II, normal and abortive fruit had an integument enclosing a massive nucellus in which an embryo sac was embedded, but embryo sac shape and constituents differed. Embryo sacs were distended in normal fruit and contained a definitive zygote as evidence of fertilization, i.e., union of egg and sperm. In contrast, embryo sacs in abortive fruit were shriveled and contained an egg apparatus as in unfertilized distillate flowers. During Drop III, normal and abortive fruit had a similar multicellular embryo. The nucellus in normal fruit was reduced to a cap at the micropyle region and cellular endosperm was evident. In contrast, the nucellus in abortive fruit was abundant and cellular endosperm was not evident. During Drop IV, embryo development in abortive fruit lagged behind that of normal fruit. Thus, we present the first direct evidence that aborted pecans deviate from normal fruit by an absence of a zygote at Drop II, a deficiency in cellular endosperm at Drop III, and a delay in embryo development at Drop IV.
\end{abstract}

Periods of pecan distillate flower and fruit abortion during the growing season have been documented by several investigators (Hamilton, 1942; Romberg and Smith, 1946; Sparks and Heath, 1972; Woodroof et al., 1928). Unlike the three major periods of drop characterized for several tree crops (Sedgley and Griffin, 1989), pecan has four drop periods including a flower drop (Drop I) and three distinctive postpollination drops (Drops II, III, and IV) (Sparks and Madden, 1985). Drop 11 marks the first period of postpollination fruit drop, Drop III the second, and Drop IV the third. Time of the drops may vary depending on geographic location and year (Sparks and Madden, 1985). Sparks and Madden (1985) extrapolated that important maturation events were associated with each drop using their results of the drop intervals and previously reported descriptions of normal anatomical pecan fruit development (McKay, 1947). Drop II, commencing as the primary endosperm nucleus divides, was proposed to be the endosperm's failing to initiate or continue development. Drop III, coinciding with early stages of embryo development, was proposed to be the absence of zygote division or embryo abortion. Drop IV, occurring at the onset of rapid cotyledon elongation, was attributed to embryo abortion. However, no direct anatomical data were presented to support these conjectures.

Certain pecan genotypes are more prone to fruit abortion than others, a situation indicative of genetic control (Sparks and Heath, 1972; Sparks and Madden, 1985). The natural predisposition of a cultivar for dropping reproductive structures has a positive influence in conservation of tree energy reserves required for quality nut production and return bloom. Identifying the sites at which abortive fruit are altered could have bearing on the fruit structure to target for analyzing the control mechanisms for fruit abortion in pecan. As no studies have examined abortive pecans anatomically for each drop, the objectives of the current study were to compare seasonal growth and anatomical development of abortive and normal fruit during Drops II, III, and IV in pecan.

Received for publication 12 May 1994. Accepted for publication 8 Sept. 1994. The technical assistance of Joyce Lambert and Donnie Maxey is gratefully acknowledged. Use of trade names does not imply endorsement of the products named nor criticism of similar ones not named. The cost of publishing this paper was defrayed in part by the payment of page charges. Under postal regulations, this paper therefore must be hereby marked advertisement solely to indicate this fact.

\section{Materials and Methods}

Selection of plant material. Normal and abortive fruit were collected from the same cluster for comparison. A spectrum of developmental stages for normal and abortive fruit exists within any given drop, as a wide gradient in development is present within a tree and among trees (Yates and Sparks, 1992). Thus, anatomical characterization was based on selected representative developmental stages.

Selection of abortive fruit was judged on periodicity of the drops (Sparks and Madden, 1985) and visual inspection. Collections were made for Drop II $\approx 3$ weeks after pollination and for Drops 111 and IV at monthly intervals thereafter i.e., $\approx 20,50$, and 80 days after full bloom for each drop, respectively. Within a drop, fruit appearance was used to identify abortive fruit. As described previously for flowers (Yates and Sparks, 1994), firmness of fruit attachment to the peduncle was a major criterion used to differentiate normal from abortive fruit. Abortive fruit were removed easily from the cluster by touching; in contrast, normal fruit had to be cut at the junction to the peduncle. Developing shucks on abortive fruit had a yellowish tinge compared to a dark green of normal fruit. Another useful marker we confirmed from an earlier report (Adair, 1932) was that shucks were removed easily from shells of abortive fruit at Drops III and IV, but adhered tightly to shells of normal fruit.

Analyses of growth. Characterization of Drop II was based on analysis of fruit collected from 'Desirable' and 'Wichita', and characterization of Drops III and IV from 'Western Schley'. Different cultivars were assessed because of variability among cultivars in the number of abortive fruit during a given drop (Sparks and Madden, 1985). A cultivar, such as 'Desirable', with a heavy Drop II, has scanty Drops III and IV. Thus, sufficient abortive fruit cannot be obtained easily during the latter drops for meaningful comparisons to normal fruit. A cultivar, such as 'Western Schley', with a light Drop II has more abortive fruit at Drops III and IV. For Drop II, four or five abortive and normal fruit were collected from each of five trees from 'Desirable' and 'Wichita'. For Drop III and IV, seven and thirteen fruit, respectively of each fruit type, were collected from 'Western Schley'. Comparisons between abortive and normal fruit and ovules within 
a drop-for length, diameter, and weight were by the t test, except ovules were not weighed. Comparisons among drops for the percent growth of abortive in relation to normal fruit and ovules were by analysis of variance with means separated by Duncan's multiple range test (Gomez and Gomez, 1984)-.

Microscopy. Tissues prepared for scanning electron microscopy (SEM) and light microscopy (LM) were fixed overnight at 4C in $4 \%$ glutaraldehyde in $0.1 \mathrm{~m}$ sodium cacodylate buffer, $\mathrm{pH} 7.2$, and dehydrated in an ethanol series. Samples for SEM were critical-point dried with $\mathrm{CO}_{2}$, mounted on stubs, coated with goldpalladium, and examined at $15 \mathrm{kV}$ with a SEM (model 505; Philips Electronic Instruments Co., Mahwah, N.J.). Samples for LM were infiltrated and embedded in resin (Spurr, 1969). Serial sections were not obtained because of the small size and tissue resiliency of ovules. Thick $0.5-\mu \mathrm{m}$ sections were cut using an ultramicrotome (model Ultracut E; Reicheti-Jung, Vienna, Austria) and stained with a mixture of $1 \%$ azure II and $1 \%$ sodium borate $(1: 1 \mathrm{v} / \mathrm{v})$ by applying gentle heat to the glass slides.

Embryo sacs were examined in cleared ovules (Herr, 1982). Ovules were fixed for 24 to $48 \mathrm{~h}$ in $\mathrm{FPA}_{50}$ [formaldehyde, propionic acid, $50 \%$ ethanol (5:5:90, by volume)], stored in $70 \%$ ethanol, and cleared for $24 \mathrm{~h}$ in BB-41/2 [lactic acid, chloral hydrate, phenol, clove oil, xylene, and benzyl benzoate $(2: 2: 2: 2: 1: 1$, by weight)]. Cleared ovules were hand-sectioned to remove the outermost layers of nucellus, mounted in BB-41/2 on Raj slides (Herr, 1982), and examined with a microscope (model $22 \mathrm{~EB}$, Leitz Dialux; LEICA, Wetslar, Germany) equipped with differential interference contrast.

\section{Results}

Seasonal growth patterns of abortive compared with normal fruit. Diameter and length of abortive fruit were $\approx 80 \%$ and fresh weight was $\approx 60 \%$ of normal fruit at Drops II and III (Fig. 1A). Size and weight of abortive fruit during Drop IV were not significantly different from their normal counterparts. Thus, size of abortive fruit compared to normal fruit increased with the seasonal progression in the drops. Within all drop intervals, ovules from abortive fruit were invariably smaller than normal fruit (Fig. 1B). Ovules in abortive fruit were $\approx 80 \%$ the diameter of those in normal fruit at Drop II, but were only $\approx 65 \%$ the diameter of normal ovules at Drops III and IV. Ovule length of abortive fruit was $\approx 80 \%$ of normal fruit regardless of the drop and did not vary significantly among the drops.

Anatomical characters associated with Drop II. Structure of the integument was similar in normal and abortive fruit (Fig. 2 A and $\mathrm{B}$, respectively). A definitive outer and inner epidermis surrounded $\approx 12$ parenchymatous cell layers. The integument extended into a bifurcation that enclosed the nucellus and accounted for $\approx 40 \%$ of the total ovular length.

The nucellus had a single layer of epidermal cells enclosing $>50$ parenchyma cell layers at the lower half of the ovule in normal and abortive fruit (Fig. $2 \mathrm{~A}$ and B, respectively). Epidermal and parenchymal cell structure was similar in abortive and normal fruit, except for the interior parenchyma cells bounding the embryo sac. These cells were equal size to other nucellar areas in ovules of normal fruit (Fig. $2 \mathrm{~A}$ and $\mathrm{C}$ ), but were much larger in abortive fruit (Fig. $2 \mathrm{~B}$ and D).

The embryo sac was embedded in the nucellus at the micropyle region of the ovule in normal and abortive fruit (Fig. $2 \mathrm{~A}$ and $\mathrm{B}$, respectively), but the shape and contents of the embryo sac were different. The embryo sac was a distended oval appressed closely to the nucellus in normal fruit (Fig. $2 \mathrm{~A}$ and $\mathrm{C}$ ), but was a convoluted rectangle detached from the nucellus in abortive fruit (Fig. 2 B and D). A dense matrix bordered the embryo sac, and structures were evident in the micropyle region but not the chalazal direction in normal and abortive fruit (Fig. 2 A-D). The structures were not identified positively in longitudinal sections of ovules.

Optical sections of cleared ovules were used to provide a definitive characterization of the entire components of the embryo sac, but not necessarily in the same focal plane (Fig. 3 A-D). Normal fruit had a zygote and a persistent synergid in the micropyle region of the embryo sac (Fig. $3 \mathrm{~A}$ and B). Some zygotes had a nucleus located in a chalazal direction and others had a centrally located nucleus. Inside the embryo sac of abortive fruit were a central nucleus and an egg apparatus consisting of an egg cell and two synergids (Fig. $3 \mathrm{C}$ and D) similar to normal flowers collected

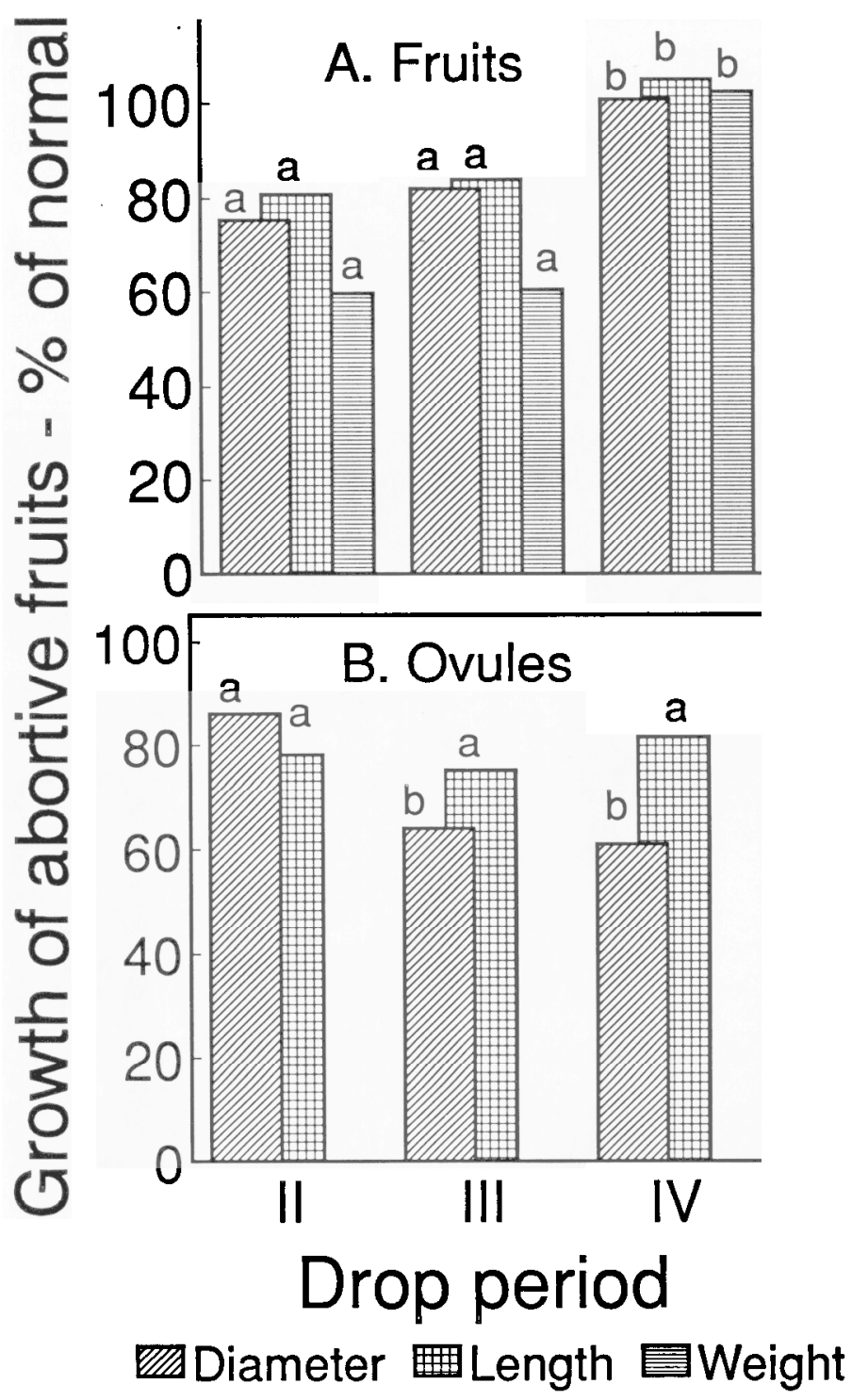

Fig. 1. Growth of abortive compared with normal pecan fruit at each drop. Normal and abortive fruit were from 'Desirable' and 'Wichita' at Drop II and from 'Western Schley' for Drops III and IV. To obtain enough fruit for meaningful comparisons, different cultivars were used for Drop II than for Drops III and IV. Drop III and IV abortive fruit are too few from a cultivar, such as 'Desirable', with a heavy Drop II, for meaningful comparisons to normal fruit. More fruit are abortive at Drops III and IV from a cultivar, such as 'Western Schley', with a light Drop II, . Within each drop, abortive fruit and ovules were significantly smaller than normal fruit and ovules, except fruit at Drop IV. Common letters above bars designate no statistical difference among drops for percent growth of abortive compared to normal fruit and ovules; $P \leq 0.05$. 


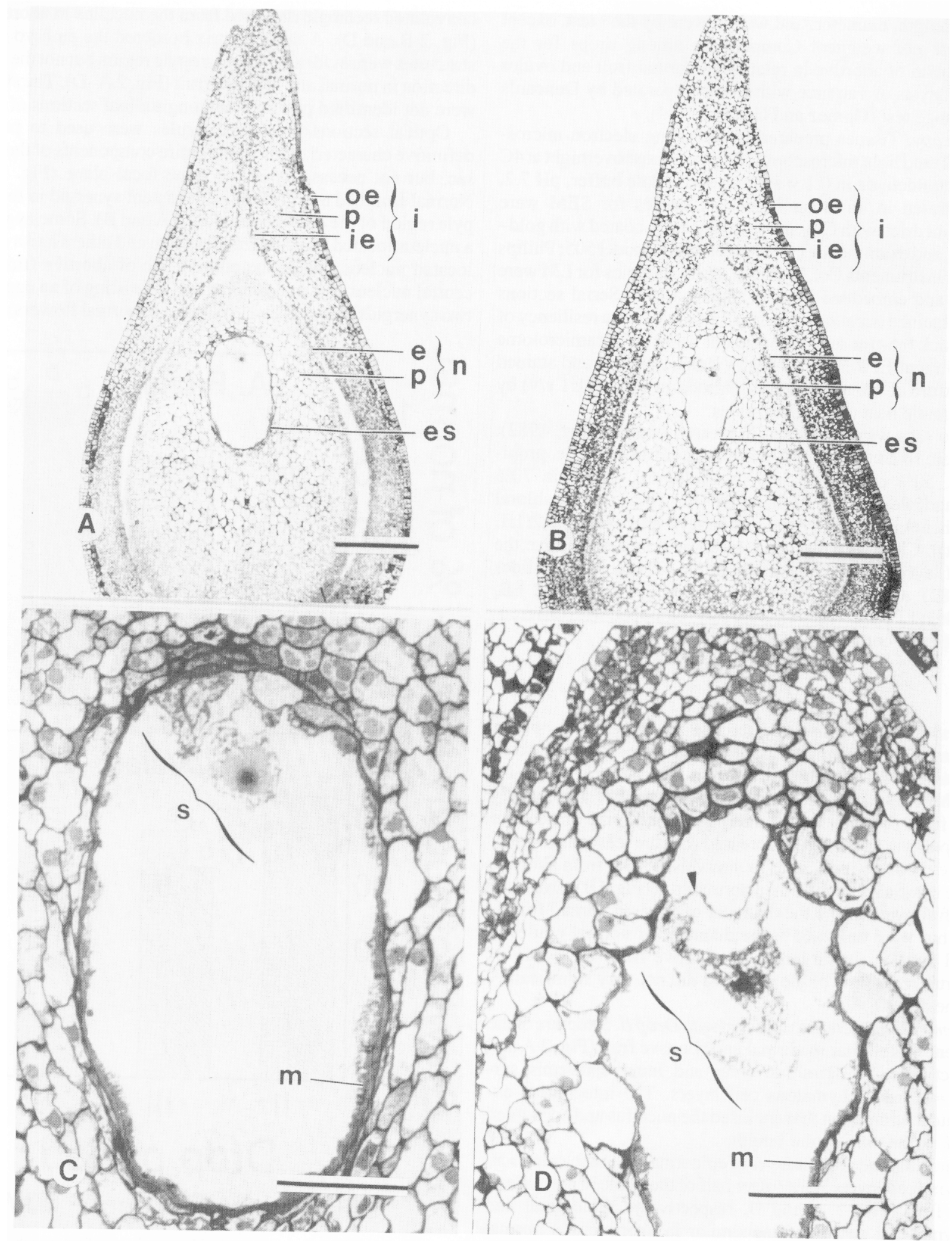

Fig. 2. Light micrographs of longitudinal sections of ovules oriented with micropyle uppermost from normal (A and $\mathbf{C}$ ) and abortive (B and $\mathbf{D})$ 'Desirable' fruit during Drop II. Ovtdes in normal and abortive fruit (A and $\mathbf{B}$, respectively) had developed an integument (i) composed of an outer and inner epidermis (oe and ie, respectively) surrounding several layers of parenchyma (p) and an embryo sac (es) embedded in a massive nucellus (n) with a single-layered epidermis (e). The embryo sac in normal and abortive fruit ( $\mathbf{C}$ and $\mathbf{D}$, respectively) was bordered by a dense matrix $(\mathrm{m})$ with structures (s) evident in the micropyle region. Embryo sacs differed in shape being distended ovals in normal $\mathbf{( C )}$ and shriveled rectangles detached from the nucellus in abortive (D, point indicates detachment) fruit. Bar $=200 \mu \mathrm{m}(\mathbf{A}$ and $\mathbf{B}), 100 \mu \mathrm{m}$ (C and D).

during Drop I (Yates and Sparks, 1994). The embryo sac was shriveled, causing the internal constituents of the embryo sac to appear distorted and/or dislodged in abortive fruit during Drop II.
Although the zygote in normal fruit and the egg in abortive fruit were about the same size, they could be easily distinguished. The cell boundary was well defined around the zygote of normal fruit 

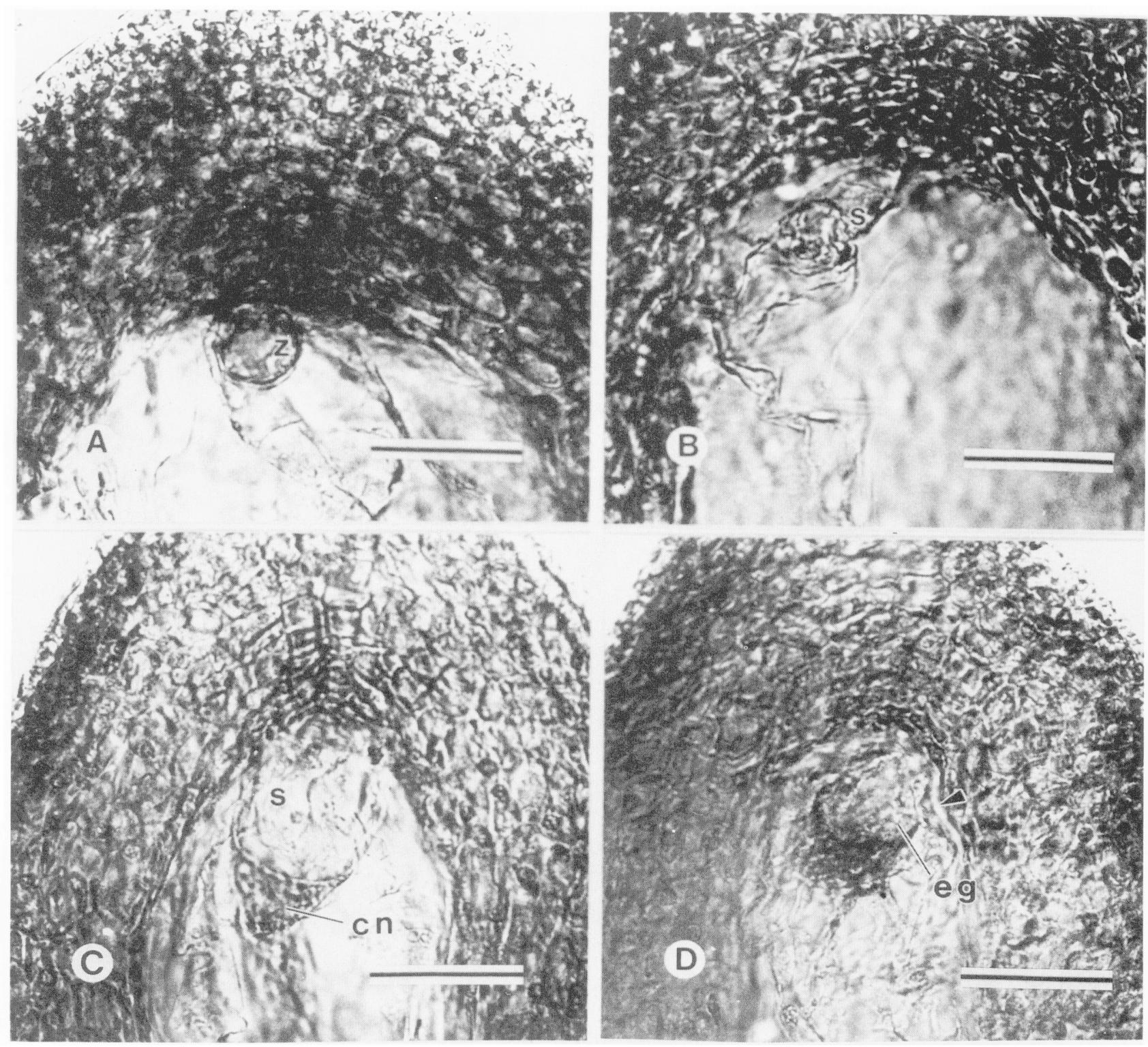

Fig. 3. Differential interference contrast micrographs of embryo sacs in cleared 'Desirable' ovules from normal (A and $\mathbf{B}$ ) and aborting (C and D) fruit during Drop II. Micrographs oriented with micropyle of ovule uppermost, with $\mathbf{A}$ and $\mathbf{B}$ being the same embryo sac, but at different focal planes. Likewise, $\mathbf{C}$ and $\mathbf{D}$ are of the same embryo sac but at different focal planes. In normal fruit, a zygote (z) with a clearly defined cell boundary was apparent in one focal plane (A) and a synergid (s) was located in another focal plane (D). A zygote was not present in aborting fruit (C and D). In embryo sacs of abortive fruit, a central nucleus (cn) and at least one synergid (s) was present in one focal plane (C) and an egg (eg) with indistinct cell boundaries was present in another plane (D). The embryo sac in Drop II abortive fruit was shriveled so that internal constituents of the embryo sac appeared distorted and/or dislodged and separation of the embryo sac from the nucellus (point) was evident (Fig. 3D). Bar= $50 \mu \mathrm{m}$.

(Fig. 3A), but was indistinct around the egg of abortive fruit (Fig. 3D). Separation of the embryo sac from the nucellus in abortive fruit was evident in optical sections of cleared ovules, as in sections of fixed ovules mentioned previously.

Anatomical characters associated with Drop III. Ovules of normal and abortive fruit at Drop III (Fig. 4 A and B, respectively) were more developed than at Drop II (Fig. 2A and B, respectively). Changes from Drop II to Drop III included an increase in the parenchyma cell layers and epidermal density of the integument, closure of the cavity between the integument and nucellus, and zygote division to forma multicellular embryo. Embryos ranging from the four-celled to globular stages were present in normal and abortive fruit by Drop III. During the globular phase of embryo development in normal and abortive fruit (Fig. $4 \mathrm{C}$ and D, respectively), the suspensor consisted of cells linearly arranged in two to three columns each composed of two to three rows. Although the stage of embryo development was not modified by fruit type, cells composing the embryo were less vacuolated in normal than abortive fruit (Fig. $4 \mathrm{C}$ and D, respectively).

Although ovules of normal and abortive fruit were similar in many aspects during Drop HI, two differences were striking. First, the nucellus in normal fruit was reduced to a cap in the micropyle region and to two or three layers of rectangular cells along the periphery of the embryo sac (Fig. 4A). The nucellus in abortive fruit was more evident, being four to five layers of irregularly shaped cells along the periphery (Fig. 4B). Secondly, the embryo 

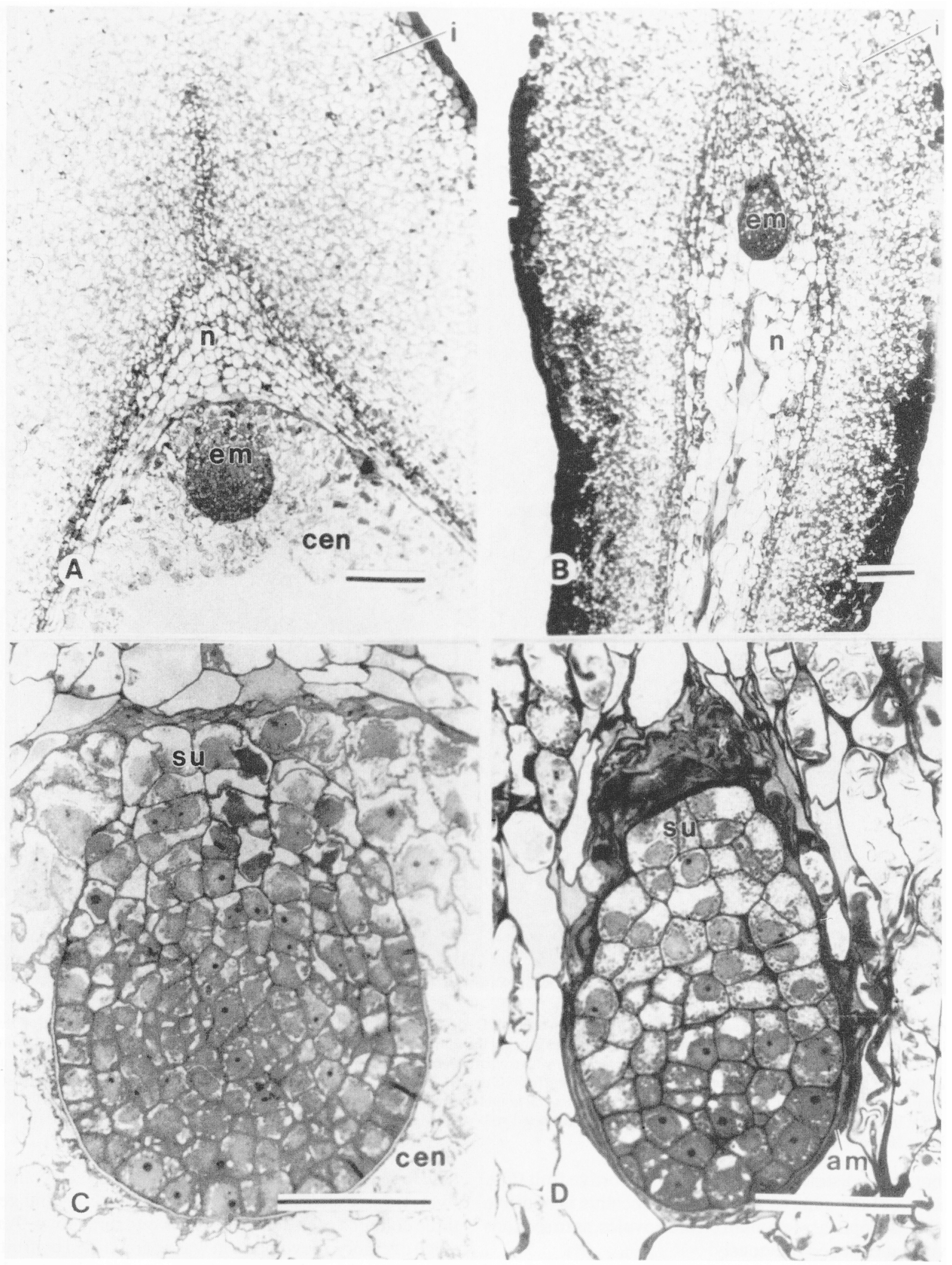

Fig. 4. Light micrographs of longitudinal sections of ovules oriented with micropyle upper most from normal (A and $\mathbf{C})$ and abortive (B and $\mathbf{D})$ 'Western Schey' fruit during Drop III Changes in normal (A) and abortive (B) ovules from Drops II to III included an increase in the cell layers and epidermal density of the integument (i), closure of the cavity between the integument and nucellus (n), and zygote division to form a multicellular embryo (em). The embryo in normal fruit (C) was surrounded by cellular endosperm (cen) and in abortive fruit (D) by an amorphous matrix (am). During the globular phase of embryo development in normal and abortive fruit (C and D, respectively), the suspensor (su) consisted of cells linearly arranged in two to three columns each composed of two to three rows. Bar= $200 \mu \mathrm{m}(\mathbf{A}$ and $\mathbf{B}), 100 \mu \mathrm{m}(\mathbf{C}$ and $\mathbf{D})$.

of normal fruit was embedded in cellular endosperm (Fig. 4A and C), which was restricted to the micropyle region of the embryo sac. Cell walls of the endosperm were very irregular. In contrast, embryos of abortive fruit were surrounded by a densely staining amorphous mass without cellular definition (Fig. 4D).

Anatomical characters associated with Drop IV. Normal and 

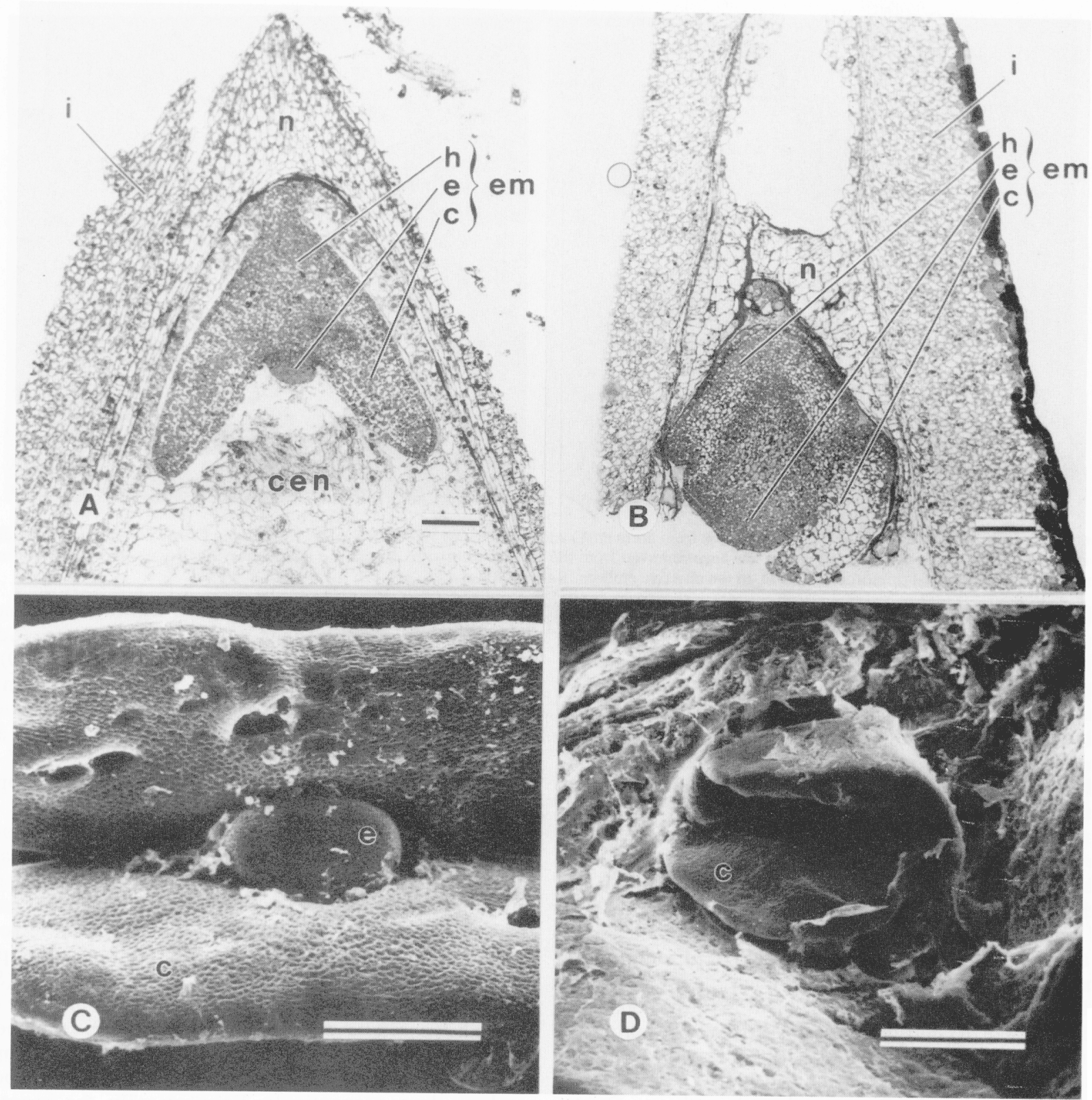

Fig. 5. Light micrographs of longitudinal sections through ovules (A and $\mathbf{B})$ and scanning electronmicrographs (C and $\mathbf{D})$ of surface features of young embryos from normal (A and C) and abortive (B and D) 'Western Schley' fruit during Drop IV. Ovules of normal (A) and abortive (B) fruit had an integument (i) and nucellus (n), and an embryo differentiated into hypocotyl (h), epicotyl (e), and cotyledon (c). Abundant cellular endosperm (ten) surrounding the embryos from normal fruit (A) was absent in abortive fruit (B). The slender, elongated cotyledons (c) spreading to reveal the epicotyl (e) in normal fruit (C) were in contrast to the thick, blunt cotylededons in aborting fruit (D). Bar $=200 \mu \mathrm{m}(\mathbf{A}$ and $\mathbf{B}), 250 \mu \mathrm{m}(\mathbf{C}), 500 \mu \mathrm{m}$ (D).

abortive fruit (Fig. $5 \mathrm{~A}$ and B, respectively) had some anatomical characters in common during Drop IV as in previous drops. Both fruit types had an integument and nucellus, and an embryo differentiated into hypocotyl, epicotyl, and cotyledon. Differences in the nucellus of normal and abortive fruit persisted in Drop IV. Only remnants of nucellus remained in normal fruit (Fig. 5A) during Drop IV, but the nucellus was still very evident in abortive fruit (Fig. 5B).

Embryos were located in the micropyle region of the ovule, with the cotyledons and epicotyl projecting toward the chalazal direction. Cellular endosperm surrounded embryos in normal fruit; whereas, nucellus surrounded embryos in abortive fruit (Fig. $5 \mathrm{~A}$ and $\mathrm{B}$, respectively). Cotyledon development in abortive fruit lagged behind that in normal fruit. Cotyledons were slender, winged structures in normal fruit (Fig. 5C), but were bulbous in abortive fruit (Fig. 5D). Embryos with differentiated leaf primordia and cotyledons extending several millimeters toward the base of the fruit were present in some normal fruit (Fig. 6A). Leaf primordia in abortive fruit were less developed (Fig. 6B) than in normal fruit.

\section{Discussion}

Based on their smaller size, abortive pecan fruit are easily distinguished from normal fruit during Drops II and III, but not Drop IV. A size reduction would not be expected at Drop IV as pecans in the southeastern United States have grown to $\approx 100 \%$ and 

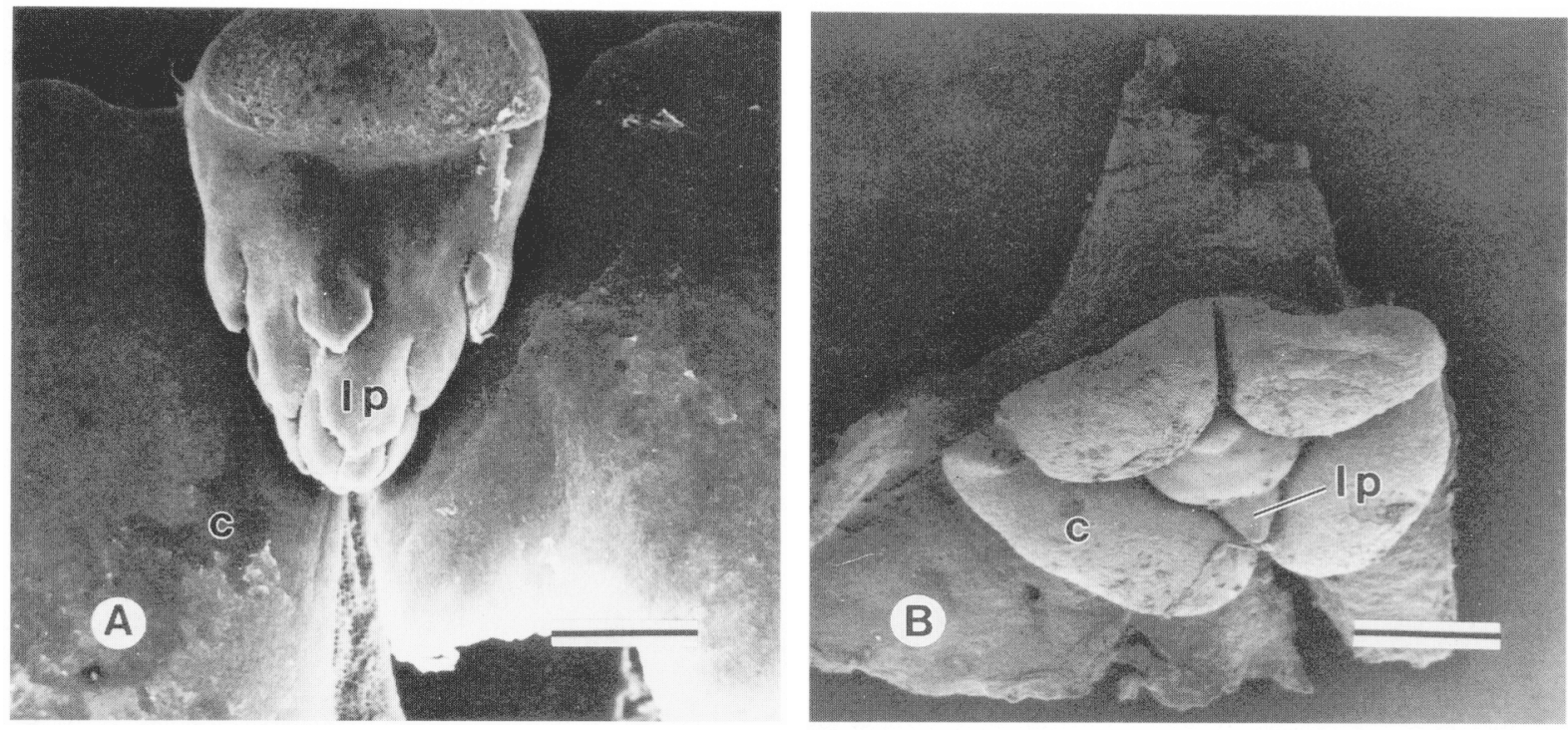

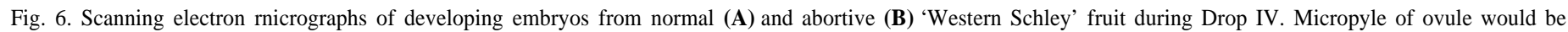

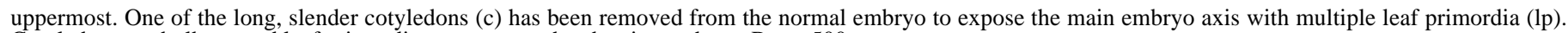
Cotyledons are bulbous and leaf primordia are scant on the abortive embryo. Bar $=500 \mu \mathrm{m}$.

$83 \%$ of their final length and width, respectively, by early August (Dozier and Amling, 1974), which is near the usual time of Drop IV, Normal and abortive fruit at Drop IV can be differentiated by internal examination, as ovules of abortive fruit are suppressed by one-third the diameter of ovules of normal fruit. In addition, ovules of abortive fruit at Drops III and IV are yellow and shriveled compared to the white and inflated ovules in normal fruit (Sparks and Madden, 1985). Ovules are brownish in fruit aborting from pest damage (Adair, 1932).

Unequivocal data have demonstrated that pollination influences Drops II and III in pecan (Sparks and Madden, 1985). All flowers bagged to prevent pollination aborted during Drop II and flowers that were self-pollinated had more abortions during Drops II and III than cross-pollinated flowers. These studies indicate that Drops II and III are due to a defect in one or both fertilization events or their products, i.e., union of the sperm nuclei either with the egg to form the zygote or with the central nucleus to form endosperrn. Faulty development of endosperm and zygote have been proposed as the cause of Drops II and III, respectively (McKay, 1947; Sparks and Madden, 1985; Romberg and Smith, 1946; Woodroof et al., 1928). However, our study disproves these hypotheses. Ovules from abortive fruit lacked a zygote at Drop II and cellular endosperm at Drop III, i.e, a reverse relationship to that proposed by earlier investigators.

Pecan is not the first plant species observed to have successful union of the egg and sperm, as evidenced by an embryo, but lacking proper endosperm formation as occurred in Drop III. Cellular endosperm surrounded the embryo in normal pecans, but was not apparent in abortive fruit. Helianthus annuus fruit with a developing embryo but no endosperm were attributed to only one fertilization event, i.e., union of sperm with egg (Newcomb, 1973). Another sequence has been reported for Podolepis jaceoides in that double fertilization occurred, but the primary endosperm nucleus failed to divide (Davis, 1961). Either of these cases could be operative in Drop III in pecan. Regardless, faulty endosperm could limit the nutrition available to support continued embryo development either as the source of the nutrients (Brink and Cooper, 1947) or as part of the transport mechanism for nutrients (Schel et al., 1984). Evidence for the endosperms providing nutrition for the developing embryo has been documented for Medicago sativa (Brink and Cooper, 1940), Zea mays (Schel et al., 1984), and Phaseolus vulgaris (Sage and Webster, 1990). A direct association of the nutritional role of endosperrn in pecan development cannot be established from the current study. Nevertheless, progression of normal endosperm development was altered in abortive pecans during Drop III. An association of deficient embryo development with Drop IV agrees with proposals by Sparks and Madden (1985).

In summary, we present the first direct evidence on growth and anatomical features altered in aborting fruit at each of the postpollination fruit drops. Size differences between normal and abortive fruit from Drop II to Drop IV became smaller for fruit, but became larger for ovules. Each drop period coincided with the initiation or continuation of important processes critical for seed development as observed in bean (Sage and Webster, 1990); neither degeneration of tissues nor distorted growth was observed. We propose that the drops be categorized by the anatomical feature impaired. Thus, Drops II, III, and IV would be identified as the zygote, endosperm, and embryo drop, respectively. Economically, the zygote drop is the significant drop, as the other fruit drops are minor and often difficult to detect (Sparks and Heath, 1972; Sparks and Madden, 1985). The zygote drop, when of significant magnitude as in 'Desirable', ensures good nut quality during the current growing season and adequate pistillate production the following year (Sparks, 1992). Limited data suggest that the endosperm drop, as well as the zygote drop, could be due in part to partial self-incompatibility (Sparks and Madden, 1985), but additional research is needed to clarify this point.

\section{Literature Cited}

Adair, H.S. 1932. Black pit of the pecan and some insects causing it. U.S. Dept. Agr. Bul. 234

Brink, R.A. and D.C. Cooper. 1940. Double fertilization and development of the seed in angiosperms. Bot. Gaz. 102:1-25.

Brink, R.A. and D.C. Cooper. 1947. The endosperm in seed development. Bet. Rev. 13:423-541.

Davis, G.L. 1961. The life history of Podolepis jaceoides (Sims) Voss. 
II. Megasporogenesis, female gametophyte and embryogeny. Phytomorphology 11:206-219.

Dozier, Jr., W. A., and H.J, Amling. 1974. Fruit growth and embryological development of the 'Stuart' pecan, Carya illinoensis. Auburn Univ. Agr. Expt. Sta. Bul. 463.

Gomez, K.A. and A.A. Gomez. 1984. Statistical procedures for agricultural research. Wiley, New York.

Hamilton, J. 1942. Studies of the premature dropping of pecan nuts. Proc. Amer. Soc. Hort. Sci. 40:159-160.

Herr, Jr., J.M. 1982. An analysis of methods for permanently mounting ovules cleared in four-and-a-half type clearing fluids. Stain Technol. 57:161-169.

McKay, J.W. 1947. Embryology of pecan. J. Agr. Res. 74:263-283.

Newcomb, W. 1973. The development of the embryo sac of sunflower Helianthus annum after fertilization. Can. J. Bet. 51:879-890.

Romberg, L.D. and C.L. Smith. 1946. Effects of cross-pollination, selfpollination, and sib-pollination on the dropping, the volume, and the kernel development of pecan nuts and on the vigor of the seedlings. Proc. Amer. Soc. Hort. Sci. 47:130-138.

Sage, T.L. and B.D. Webster. 1990. Seed abortion in Phaseolus vulgaris L. Bet. Gaz. 151:167-175.
Schel, J. H. N., H. Kieft, and A.A.M. VanLammeren. 1984. Interactions between embryo and endosperm during early developmental stages of maize caryopses (Zea mays). Can. J. Bet. 62:2842-2853.

Sedgley, M. and A.R. Griffin. 1989. Sexual reproduction of tree crops. Academic, San Diego.

Sparks, D. 1992. Pecan cultivar-The orchard's foundation. Pecan Productions Innovations, Watkinsville, Ga.

Sparks, D. and J.L. Heath. 1972. Distillate flower and fruit drop of pecan as a function of time and shoot length. HortScience 7:402-404.

Sparks, D. and G.D. Madden. 1985. Pistillate flower and fruit abortion in pecan as a function of cultivar, time, and pollination. J. Amer. Soc. Hort. Sci. 110:219-223.

Spurr, A.R. 1969. A low-viscosity epoxy resin embedding medium for electron microscopy. J. Ultrastructure Res. 26:31-43.

Woodroof, J. G., N.C. Woodroof, and J.E. Bailey. 1928. Unfruitfulness of the pecan. Georgia. Expt. Sta. Bul. 148.

Yates, LE. and D. Sparks. 1992. External morphological characteristics for histogenesis in pecan anthers. J. Am. Soc. Hort. Sci. 117:181-189.

Yates, I.E. and D. Sparks. 1994. Anatomy differs for aborting and nonabortingpistillate flowers in pecan. J. Amer. Soc. Hort. Sci. 119:949_ 955. 